\title{
The Difficulties and Countermeasures of Xinjiang Governance System and Capacity Modernization Construction
}

\author{
Liu $\mathrm{Na}$ \\ Tarim University, Alar City, Xinjiang, 843300, China \\ 346591653@163.com
}

Keywords: Xinjiang; governance system; governance capacity; modernization construction

\begin{abstract}
In the process of promoting the modernization of national governance systems and governance capacity, Xinjiang needs to deal with many problems and the situation is very complicated. Actively combing and summarizing the important significance of promoting the modernization of governance systems and governance capacity in Xinjiang is very necessary. At first, this paper analyzes the status of social governance in Xinjiang, and then discusses the problems existed in Xinjiang social governance system and governance capacity modernization, finally puts forward the path for Xinjiang to promote the modernization of governance systems and governance capacity.
\end{abstract}

\section{Introduction}

The Third Plenary Session of the eighteen CPC Central Committee regards "Improving and developing the socialist system with Chinese characteristics, modernizing the national governance system and capabilities" as the overall goal of deepening reform. The second central Xinjiang Work Forum put forward to promote the modernization of governance systems and governance capacity in Xinjiang, to achieve the rule of law, unity and stability. This highlights, in the path of the modernization of governance systems and governance capacity in Xinjiang, it has to be accommodated in the national governance system and governance capacity modernization of the mainstream, but also with social stability and long-term stability.

\section{Current Situation of Social Governance in Xinjiang}

Facing the complicated and grim situation and arduous tasks, Xinjiang has done a lot of work in the fight against violent terrorist activities, curbing religious extremism thought, reinforcing the basic safeguard, improving people's livelihood, and promoting national unity. In 2014, for the implementation of the central spirit, Xinjiang Autonomous Region Party focused on the social stability and long-term stability, carried out a large-scale livelihood activities aimed at contact with the masses, cadres training, strengthening grass-roots, carried out special operations to crack down on violent terrorist activities. Adhere to the modern culture for the lead, promote an integrated pluralistic, respect differences, inclusive and diverse culture, create contacts and exchanges between the promotion of national integration, resist religious extremism think; carry out a clean government and combat corruption, strive to build a high-quality cadres team.

The main objective of the current governance in Xinjiang is to maintain social stability and 
long-term stability. Many factors affect social stability, such as land expropriation, housing demolition, environmental issues, officials of corruption and so on, which is far more complex in Xinjiang affected by many factors at home and abroad, such as the social situation change, international hostile forces infiltration, ethnic separatists, religious extremists and Xinjiang's economic development is lagging behind, these problems lead Xinjiang governance is difficult. Currently, Social Governance in Xinjiang mainly implemented in the following aspects: First, strengthen maintaining stability, crack down on violent terrorist activities, adhere to anti-violence, adhere to the rule of law and order; Second, curb religious extremism ideology, protect the legitimate religion, combat the crime and illegal religious; Third, strengthen the building of grassroots organizations to improve the capacity of rural and community management and service; Fourth, strengthen the management of floating population, especially to improve the ability to control the outflow of the population in the southern border; Fifth, promote national unity and work to improve the social relations; Sixth, promote the spread of modern cultural activities and thinking, strengthen education and management in the ideological field; At the same time, increase investment in the vital interests of the people to solve the matter of housing, income, employment, education and other issues, do efforts to protect and improve people's livelihood, become the most important way of winning hearts and minds.

In particular control work, it has the following characteristics: First, ethnic issues and religious issues, this is a special and complex problems of Xinjiang issue, so in control work, it should give priority to the management of religious affairs; Second, the development and stability are the two support to solve the problem in Xinjiang; Third, strengthen the building of grassroots organizations; Fourth, focus on all types of destabilizing people and focus on the floating population; Fifth, promote modern culture as a guide and pay attention to the protection of national traditional culture.

\section{The Problems Existing in Xinjiang Social Governance System and Governance Capacity Modernization}

Coping strategies are numerous, but it lacks of a systematic, long-term strategic plan. One of the characteristics of modern social governance is systemic, holistic and long-term. At present, in Xinjiang social governance, systematic and long-term are insufficient, the short-term governance is poor, and the government is passively to response, which even will bring many obstacles to achieve long-term goal. Governments at all levels need to go from the current most urgent reality, all service for stability, objectively, it can not be a lasting effort to condone the way, all kinds of emergency, coping mechanisms, often evolve into expedient Governance, campaign-style governance, which is difficult to sustain. Some governance policies lack of comprehensive consideration, or did not follow the objective law of development of things, so it is difficult to achieve the desired effect. For example, promoting bilingual teaching in Xinjiang can improve the ability of minority students use of national common language, so it is a long-term fundamental strategy. In recent years, the state investment is large, but also achieved remarkable results. However, in some areas due to pushing too fast, limited by language teachers and social environment, the teaching quality is affected. Part of the management personnel lack of understanding and long-term strategic considering. For example, in the management of religious affairs, some managers believe that religion is a deep-rooted problems, by means prohibitive, restrictive measures, it can reduce the religious activities. In fact, it may stimulate some religious people's rights psychology due to improper management practices. 
Governance mode lacks of unity and coordination. In modern society, interpersonal communication increases, and society is becoming more and more complex, social problems broke through the fixed area and a single department, and crossing border characteristics becomes more and more obvious,such as environmental pollution, crime, infectious diseases, floating population, traffic congestion, financial risks and other social problems, they all need to carry out collaborative governance. Modern social governance focuses balance and coordination, multi-stakeholder, multi-sectoral coordination, but in the way of governance, between regional and inter departmental unity, the phenomenon lacking of coordination is more, especially in the responsibility of maintaining stability, each department just cares their own affairs. Taking the management of floating population as an example, more and more rural population entering the town is the social development trend, but there are a lot of non adaptation for the rural transfer to cities and towns, and they are easily influenced by the religious extremist ideology, they are the focusing objects of dimensional stability work. Thus, on the one hand, in the outflow of migrants, the local government should improve the income of local farmers and increase their knowledge, on the other hand, in the inflow, as the management side fears that the floating population increasing will increase the cost and difficulty of social management, they tend to increase the inflow threshold, ascend into difficulty, thus it brings a greater inconvenience for migrants local integration, and the objective is not conducive to social stability and long-term stability.

In the management means, social organizations and public participation is deficiency. An important feature of modern governance is the diversity of management body. In general, the invisible hand of the market allocates economic resources, mainly follows the principle of efficiency; Government protects order and allocation of public goods, mainly follows the principle of equity; The society maintain the basic public life, follows the main principle of autonomy; In Xinjiang, the social development is inadequate and the social organizational strength is weak. Performance in the grass-roots community governance, the staff composition, sources of funding, job responsibilities of urban communities and rural villages Governing Body have a strong administrative color, actually also have been or are being build to form an administrative agency. This is determined by the current situation of Xinjiang complex social stability and grim reality needs, which reflects the Xinjiang Communist Party and government attach great importance to the building of grassroots organizations. Of course, these problems are not unique to in Xinjiang, local governments affected by the traditional "official position" culture and "efficiency first" thinking, in the decision-making process, citizen participation is excluded, so it directly results that the local decision-making speed is fast, but in the execution, it is protested by groups, eventually forced to give up decision-making, the situation is not uncommon in the the country .

\section{The Path for Xinjiang to Promote the Modernization of Governance Systems and Governance Capacity}

Construct local regulations, implementation and monitoring system complying with the actual Xinjiang. Modern society is a society ruled by law. In social governance, the rule of law is a prerequisite, Xinjiang is a region with a multi-ethnic, multi-religious, multi-cultural, only governance according to law can ensure social justice and social order. In conjunction with the actual Xinjiang, open up a path in line with the rule of law situation in Xinjiang region characteristics. One disadvantage of traditional management system is excessive government intervention, and everything depends on government control, as a result, society loses momentum, 
since the government took on too much responsibility, it bear the negative. Modern social governance gives more emphasis on "Interaction" features, governments implement management, service control for public affairs, and social implements supervise and criticism for the government.

Improve the profit distribution mechanism and increase public self-development capacity. Modern governance focuses on the source of governance and accelerating economic development, making the fruits of development more and more equitably benefit all the people. Improving the material and cultural living standards of the people is the important source and means of governance.

Improve all aspects of communication and coordination mechanism and enhance overall planning capacity. One of the important characteristics of modern social governance is co-ordination, co-ordinate all parties governance body and coordinate different interest groups to play their best to get what they want. In Xinjiang, the governance of co-ordination is more important. Specific measures: establish and improve various types of cross-sectoral, lateral communication and coordination mechanisms, including the Social Security Protection System administrative area, population outflow and inflow.

Improve the working mechanism of the masses. Comrade $\mathrm{Xi}$ Jinping pointed out that the largest mass work in Xinjiang is national unity and religious harmony. Mass work, including understanding the masses, serving the people, guiding the masses and asking the masses, and its premise is to believe in the people and respect the people, the goal is to get the recognition and support of the masses. Some cadres think the masses is ignorant, ignore the reasonable demands and the legitimate rights and interests of the masses. Only emphasizing educating the masses can not get public support even into the grassroots.

Building a harmonious society relations mechanism, enhance the ability to communicate in different social groups. Xinjiang is a multi-ethnic, multi-religious, multi-cultural region, and promoting the harmonious interaction of different social groups is the basic condition for the establishment of a harmonious society. The most long-term problems in Xinjiang is ethnic solidarity. National unity, to the social behavior, is interpersonal solidarity, which is reflected in mutual understanding tolerance, equality and mutual assistance and harmony.

\section{References}

[1] Mo Jihong. On "national governance systems and governance capacity modernization" of "the spirit of the rule of law" [J]. Journal of Xinjiang Normal University (PHILOSOPHY AND SOCIAL SCIENCES EDITION), 2014,03:15-20+2.

[2] Mo Jihong. National governance systems and governance capacity modernization and legalization of [J]. Law Journal, 2014,04:21-28.

[3] He Huixing, Sun Song. On the modernization of the governance system and governance capacity of universities [J]. higher education of agriculture, 2014,09:3-6. 
[4] Du Feijin. A new dimension of China's Modernization -- on the modernization of national governance system and governance capacity [J]. social science research, 2014,05:37-53.

[5] Gao Yanyan, Chao Yanhua.The outstanding problems of Xinjiang governance system and governance capacity modernization faced by [J]. chizi (MID), 2015,06:11-12.

[6] Li Xiaoxia. On the modernization of Xinjiang governance system and governance capacity [J]. Journal of Xinjiang Normal University (PHILOSOPHY AND SOCIAL SCIENCE EDITION), 2015,06:73-78. 